\title{
Natural Gas Utility Machinery Technologies
}

\author{
${ }^{1}$ Larisa M. Gabsalikhova, ${ }^{2}$ Irina V. Makarova, ${ }^{3}$ Eduard M. Mukhametdinov \\ ${ }^{1-3}$ Kazan Federal University \\ Email: muhametdinoval@mail.ru
}

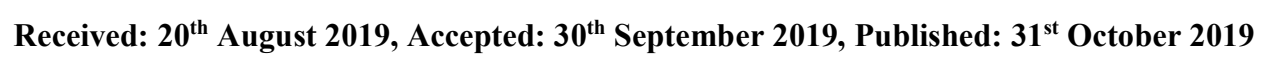

\begin{abstract}
Due to its properties, natural gas can be used in all transport segments. Compressed natural gas is effective in transport, which is operated in urban locations. This is passenger, light freight transport, utility machinery. The environmental impact of large fleets is higher than personal vehicles due to large annual mileage, so the fleets of trucks operating in the cities (municipal vehicles, buses) are the most significant for the introduction of new innovative solutions in terms of improving the environmental friendliness of vehicles. The problem of collecting municipal waste and its disposal are among the most important utilities. Vehicles for the export of solid household waste on compressed natural gas will reduce harmful emissions into the environment and create less noise compared to diesel counterparts, which is especially true in the morning. We considered the main manufacturers of garbage trucks in Russia. The trend of recent years is an increase in the proportion of rear-loading garbage trucks, which are gradually crowding out the rest. To form a natural gas automobile market, it is necessary to develop a service infrastructure: system of gas stations and fuel delivery, diagnostic and service centers. We also considered the issues of ensuring the required service quality for gas vehicles. One of the factors affecting the reliability of a vehicle is the quality and reliability of its components, assemblies and systems. We analyzed the defects of gas equipment and offered an adjustment of the maintenance process for gas equipment.
\end{abstract}

\section{Keywords}

Garbage Truck, Environmental Friendliness, Compressed Natural Gas.

\section{Introduction}

Urban pollution is a growing concern for the effects on human health. The key factors that affect air pollution from automobile transport include low environmental performance of vehicles produced in the country, low quality of motor fuel, and increase in international and intercity traffic [1]. Natural gas is considered an alternative type of fuel that can best replace conventional fuels in order to reduce their environmental impact. The control of pollutant emissions from vehicles that travel along fixed routes on a daily basis, such as buses and garbage collection vehicles, is very important. The fleet of utility machinery used to restore order in the cities and on the roads is extremely diverse. The utility machinery is designed for year-round maintenance and cleaning of roads, city streets, courtyards from garbage, removal of municipal solid waste to special landfills. The production of this type of equipment and machinery occupies a worthy place in the automotive industry.

More than 150 models of garbage trucks are produced in Russia, which differ in the basic chassis, loading and unloading method, mass of transported garbage, garbage compaction coefficient in the body, as well as in the design of the main equipment components and the external design. The share of garbage trucks in the total volume of utility machinery is on average about 35\% in Russia. About 2-2.5 thousand new cars are replenished during the year.

Garbage trucks are one of the most popular types of utility machinery. They have long become an integral part of the life of large and small cities. The use of compressed natural gas as a motor fuel can significantly reduce the environmental impact of exhaust gases, as well as achieve significant operational savings due to the low cost compared to petroleum types of motor fuel, which is especially important for garbage trucks traveling many kilometers a day. The issues of increasing the production of automotive vehicles operating on natural gas (methane), as well as expanding the gas filling infrastructure in Russia, are discussed at the government level. These steps, as well as rising oil prices, shall significantly increase the demand for gas engine fuel.

\section{Methods}

In accordance with the European legislation, state, municipal and private companies with the necessary permissions have the right to collect, transport and process waste. Currently, waste management is one of the problems that spend a lot of money around the world. A key issue in waste management is collection, sorting and transportation. Most studies are devoted to determining the effectiveness of waste transportation system and drawing up the most optimal route [2, 3]. In the study [4], a model is programmed to optimize the transportation of garbage, taking into account the type of vehicle, distance traveled, maximum vehicle carrying capacity and maximum landfill capacity.

The use of new technologies can lead to a significant improvement in the waste management process. The first stage is to monitor the waste volume and content in the trash can, the second stage is the planning and routing of vehicles for waste collection based on the information from garbage cans [5]. Filling trash cans create an unsanitary environment. A smart trash can warns that it is full and sends garbage trucks to garbage collection [6, 7]. As soon as the garbage can reaches the maximum level, the waste management department receives an SMS notification so that the department can 
send the waste collection vehicle to the appropriate garbage collection area [8]. As a result of changes in the waste management industry, the logistics of garbage collection are changing in the regions. It appears a stage of sorting and transporting sorted raw materials by processors and a stage of using information technology in waste management.

The use of alternative fuel-powered garbage trucks is expanding throughout Europe. When disposing old garbage trucks with diesel engines, the companies involved in garbage collection are increasingly choosing vehicles with hybrid drives or engines powered by compressed natural gas $(\mathrm{CNG})$ and biomethane. To solve the environmental problems of the cities, the scientists develop and test hybrid garbage trucks $[9,10]$.

One approach to reducing harmful emissions from a car is to use compressed natural gas vehicles that have lower NOx emissions than diesel vehicles [11,12,13]. The study [11] shows the test results carried out on vehicles for garbage collection, in terms of their energy consumption and pollutant emissions. The following fuels are analyzed: diesel, biodiesel (B50 and B100) and compressed natural gas (CNG).

Gas is an environmentally friendly fuel that surpasses gasoline in its properties. A diesel garbage truck meeting the Euro VI standards was tested both in the laboratory on a dynamometer and during operation.. It was found that the use of diesel garbage trucks (Euro 6) in the cities will require a further reduction in actual NOx emissions (other pollutants were very low) [14]. There is a huge improvement compared to old technologies; however, the ultimate goal is to achieve near zero emissions.

Utility equipment has a constant route and daily consumes a large amount of fuel, therefore it is one of the priority segments for the development of the gas engine industry. The issues of increasing the production of automotive vehicles operating on natural gas (methane), as well as expanding the gas filling infrastructure in Russia, are discussed at the government level. These steps, as well as rising oil prices, shall significantly increase the demand for gas engine fuel.

\section{Results and Discussion}

The Market of Garbage Trucks in Russia.

Today, the main manufacturers of utility machinery in Russia are leading engineering companies, including: Arzamas Plant of Utility Mechanical Engineering OJSC (Arzamas, Nizhny Novgorod Region); Ryazhsky Car Repair Plant OJSC (Ryazhsk, Ryazan Region); Mtsensk Plant of Utility Mechanical Engineering OJSC (Mtsensk, Orel Region), RGTechno (Lyubertsy, Moscow Region).

Five main groups are distinguished by the garbage loading method: garbage trucks with side and rear loading, container garbage trucks, front-loading garbage trucks.

The trend of recent years is an increase in the proportion of rear-loading garbage trucks, which are gradually crowding out the rest. The use of a pressing system in garbage trucks with rear loading can increase the compaction ratio of garbage up to 9, while this coefficient does not exceed 2.5-4 in garbage trucks with side loading, which increases the mass of garbage being removed and reduces operating costs by reducing the required number of special equipment units. The use of rear loading technology allows solving environmental problems by eliminating the scattering of garbage when loading the container, since loading is carried out in the dimensions of the waste bin, and not through a small funnel on the roof of the garbage container, as with side loading. Working with the tipping mechanism on garbage trucks with rear loading is much safer for the machine operator, since the container is lifted to a height of $1.5-1.8 \mathrm{~m}$ from the ground, and not 2.5-3 $\mathrm{m}$ as with side loading. The use of containers on wheels allows feeding them to the place of unloading from places where the vehicle cannot drive close. The rear loading garbage truck can be loaded manually. With lateral loading, loading can be carried out only from containers of a given type.

The development of the gas engine market is hindered by a number of problems: undeveloped and fragmented infrastructure with concentration in certain regions; outdated legal framework; small amount of methane transport.

\section{After-Sales Service for Compressed Natural Gas Vehicles.}

Issues of service and warranty are closely related to issues of equipment quality and its installation on the chassis in the manufacture of special equipment. In order to develop the market for gas vehicles (GV) on compressed natural gas, it is necessary to ensure the infrastructure development: a system of gas stations and fuel delivery, diagnostic and service centers, as well as to train qualified personnel, since there are problems with the quality of service for gas vehicles in the existing service centers. This is due to the specific nature of technological processes of technical maintenance (TM) and current repair (CR) of gas vehicles. It is necessary to equip service centers for service maintenance of gas vehicles. The following shall be organized on the territory of the service center: a post for checking the tightness of gas equipment (GE); gas release (accumulation) and cylinder degassing post; specialized site for TM and CR of gas equipment; a warehouse for storing empty degassed vehicle cylinders for CNG; open areas for storage of GV.

Technological process of the first gas equipment maintenance TM-1 is presented in Figure 1. 

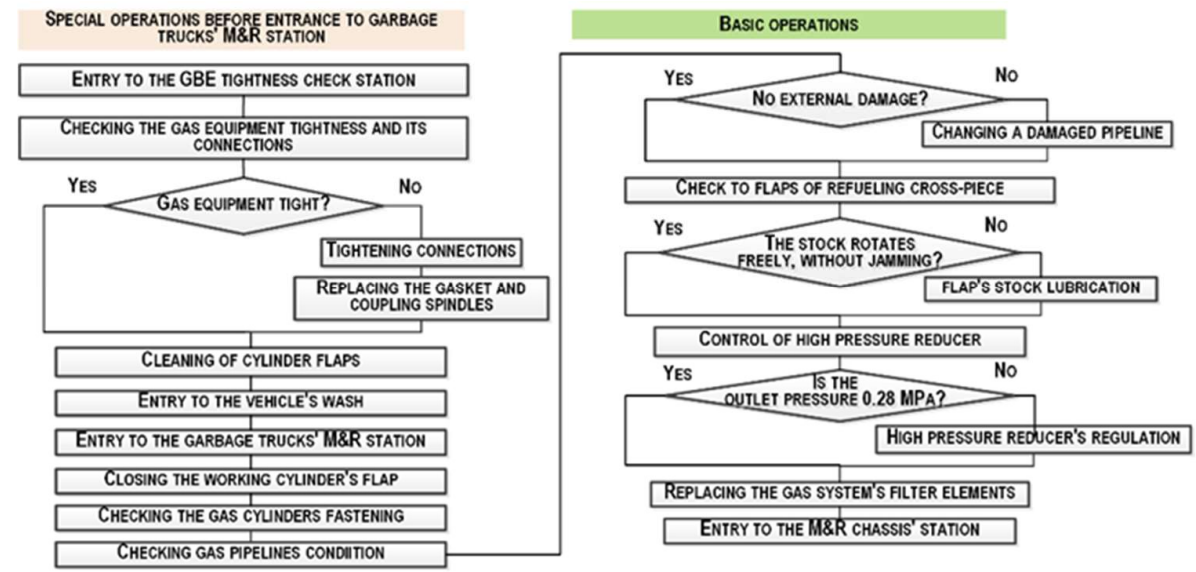

Fig. 1: Technological Process of Gas Equipment Maintenance

TM-1 GV includes such tasks as checking the condition and fastening gas cylinders and brackets, filling and consumable fittings, and checking the tightness of the gas supply system.

TM-2 GV involves the following operations: checking the condition and fastening of gas cylinders to the brackets; checking the condition and mounting of the brackets to the body or platform; and for some car models - mounting sections of the cylinders to the vehicle frame; checking the condition and fastening of the filling and flow valves and gas pipelines; checking and, if necessary, adjusting the high pressure reducer to working pressure; leak test of the gas power system; diagnostic work of the engine management system.

Seasonal GV maintenance is performed 2 times a year and combined with the next TM-2. When conducting SM, it is necessary: to tighten the fastening of gas cylinders to the brackets; tighten the bracket mounting to the platform, as well as tighten the cylinder section mounting to the vehicle frame; to check the tightness of the gas supply system; to check the high pressure gauge, seal and stamp with the next inspection period.

The defects of gas equipment that arose during the operation of automobiles (vehicle mileage from $25-30$ thousand $\mathrm{km}$ ) were analyzed according to data from the operating organization of compressed natural gas equipment.

The analysis of complaints showed that the largest number of failures occurred at gas meters, gas valves and phase sensors (Figure 2). The FMEA results served as the basis for adjusting the technological process for the maintenance of gas equipment. It is offered to add the verification of these elements of the gas power system shall be added to the technological process of the first maintenance MT-1 during the main operation period. This allowed reducing the number of failures in the gas supply system by improving the quality of processes and preventing sudden failures, which increases the reliability and safety of gas communal vehicles.
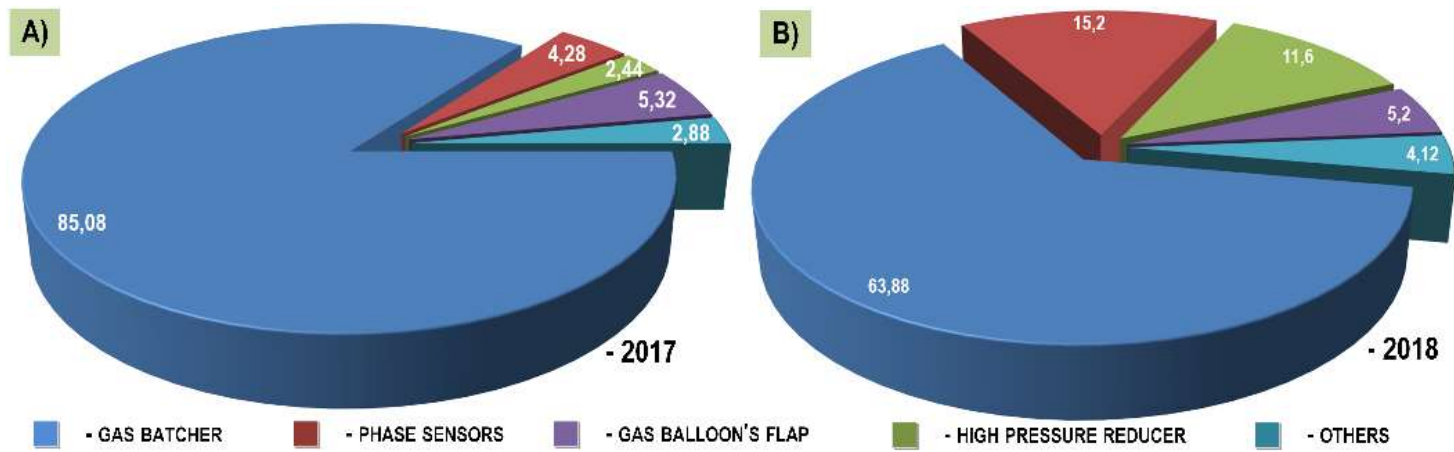

Fig. 2: Shares of Gas Equipment's Reclamations (A) - Before to the Measures Implementation to Improve Processes; C) After the Measures Implementation)

For the engine, the TM terms are calculated by the worked hours, and for the chassis - by mileage in km. This is especially true for garbage trucks, because these special vehicles do not drive at high speeds so that the engine hours can be counted by mileage, as is done for long-haul trucks. After running the first $800-1,000 \mathrm{~km}$, the mechanic shall replace the engine oil and filters: oil and fuel. The design feature of KAMAZ gas engines (820.73, 820.74, 820.60, 820.61 ) is the presence of turbocharger, charge air cooler, electronic control and exhaust gas aftertreatment system. The operational experience of KAMAZ vehicles shows that the main failures in gas engines during the warranty period occur in the first $8,000 \mathrm{~km}$ of run [1], therefore it is necessary to investigate the causes of failures.

The service life of the garbage truck can be up to 10-15 years. The vehicle durability directly depends on the quality of its maintenance. Regular maintenance is cheaper than unplanned repairs and equipment idle. Another way to reduce maintenance is to rationally make routes for garbage trucks, avoiding extra kilometers and thereby reducing machine wear. The routes shall not cross, the garbage trucks shall not go back along the previously traveled path and turn $180^{\circ}$, 
cross the transport stream in order to empty containers with garbage. All drivers shall work with the same load throughout the entire 8-hour shift. When drawing up the maintenance program, the operating conditions and environmental influences shall be taken into account. For example, when working in mountainous or hilly areas, brake shoe linings wear out faster, tire cord can be damaged in extreme heat, and garbage trucks that call on a garbage dump station and solid domestic waste landfills often suffer damage typical for off-road driving.

\section{Summary}

The issues of collection and disposal of household and industrial waste in the current period are considered the most important in the field of conservation and improvement of the environment. Garbage machines are one of the most intensively operated types of urban equipment. Every day they take tons of household garbage to landfills and ensure the environmental safety of the cities. Severe operating conditions often lead to various breakdowns, so it is necessary to timely carry out maintenance and repair of garbage trucks.

\section{Conclusions}

In search of environmental benefits, developed countries have been trying to increase the use of alternative fuels in transport for many years. The process of mass introduction of alternative fuels is inevitable, as it is determined by objective reasons for the limited oil reserves in the world and increasing environmental requirements. The greatest prospects, especially in our country, are those alternative types of fuel, the initial basis of which is natural gas. Natural gas garbage trucks are environmentally friendly, economical, and generate less noise. To develop the compressed natural gas automobile market, it is necessary to ensure the development of the infrastructure for refueling and service support of this type of equipment.

However, the issue of the uptime of utility vehicles remains important. Improving the quality of warranty service is provided by the improvement of technological processes and by preventing sudden failures.

\section{Acknowledgements}

The work is performed according to the Russian Government Program of Competitive Growth of Kazan Federal University.

\section{References}

[1] L. Gabsalikhova, G. Sadygova, I. Makarova, E. Mukhametdinov, "The prospects of use of alternative types of fuel in road transport', Journal of Fundamental and Applied Scienses, vol.9, № 2S, pp. 869-879, 2017.

[2] S Hariyani, C Meidiana, "Optimization of waste transportation route at waste transfers point in Lowokwaru District, Malang City“, IOP Conf. Ser.: Earth Environ. Sci., vol. 148, conference 1. 012031, 2018, doi :10.1088/17551315/148/1/012031

[3] Hartatik, A. Purbayu, L.Triyono, "Dijkstra Methode for Optimalize Recommendation System of Garbage Transportation Time in Surakarta City“, IOP Conf. Ser.: Mater. Sci. Eng., volume 333, Number 1. 012106 ,2018, doi:10.1088/1757-899X/333/1/012106

[4] Y. Sutanto, S. H. E. Friantin and S. Wulandari, "Integer Programming Model to Optimize Waste Management System (Case Study: Surakarta City Indonesia)“, 18th International Conference on Parallel and Distributed Computing, Applications and Technologies (PDCAT), Taipei, pp. 495-497, 2017

[5] Aleyadeh and A. M. Taha, "An IoT-Based Architecture for Waste Management", 2018 IEEE International Conference on Communications Workshops (ICC Workshops), Kansas City, MO, , pp. 1-4, 2018.

[6] C. J. Baby, H. Singh, A. Srivastava, R. Dhawan and P. Mahalakshmi, "Smart bin: An intelligent waste alert and prediction system using machine learning approach“, 2017 International Conference on Wireless Communications, Signal Processing and Networking (WiSPNET), Chennai, 2017, pp. 771-774.

[7] A. Sathish, M. Prakash, S. A. K. Jainulabudeen and R. Sathishkumar, "Intellectual trash management using Internet of Things“, 2017 International Conference on Computation of Power, Energy Information and Commuincation (ICCPEIC), Melmaruvathur, 2017, pp. 053-057.

[8] K. Nirde, P. S. Mulay and U. M. Chaskar, "IoT based solid waste management system for smart city", 2017 International Conference on Intelligent Computing and Control Systems (ICICCS), Madurai, 2017, pp. 666-669.

[9] H. Lee, T. Hirota, Y. Ihara, T. Yamaura and Y. Kamiya, "A Study on Hybrid Power Plant System of Fuel Cell and Li-Ion Battery for Garbage Truck“, 2017 IEEE Vehicle Power and Propulsion Conference (VPPC), Belfort, 2017, pp. 16.

[10] E.Cortez, M. Moreno-Eguilaz and F. Soriano, "Advanced Methodology for the Optimal Sizing of the Energy Storage System in a Hybrid Electric Refuse Collector Vehicle Using Real Routes“, Energies 2018, vol 11, 3279, 2018 doi.org/10.3390/en11123279

[11] J. López, N. Flores, F. Jiménez, F. Aparicio, "Emissions pollutant from diesel, biodiesel and natural gas refuse collection vehicles in urban areas", Highway and Urban Environment., Part of the Alliance for Global Sustainability Bookseries , vol.17, pp. 141-148, 2009, DOI https://doi.org/10.1007/978-90-481-3043-6_16

[12] G. Karavalakis, Y. Jiang, J. Yang, M. Hajbabaei, K. Johnson, T. Durbin, "Gaseous and Particulate Emissions from a Waste Hauler Equipped with a Stoichiometric Natural Gas Engine on Different Fuel Compositions", SAE Technical 
Paper, 2016-01-0799; Society of Automotive Engineers, Inc.: Detroit, MI, USA, 2016, DOI: https://doi.org/10.4271/2016-01-0799

[13] C. Misra, C. Ruehl, J. Collins, D. Chernich, J. Herner, "In-use NOx emissions from diesel and liquefied natural gas refuse trucks equipped with SCR and TWC, respectively“, Environ. Sci. Technol, vol.51, p.p.6981-6989,2017.

[14] B. Giechaskiel, R. Gioria, M. Carriero, T. Lähde, F. Forloni, A. Perujo, G. Martini, Luigi Maurizio Bissi and R. Terenghi, "Emission Factors of a Euro VI Heavy-Duty Diesel Refuse Collection Vehicle“, Sustainability, vol. 11(4), 1067, 2019 DOI: https://doi.org/10.3390/su11041067

[15] Garbage truck: let's check health. URL: https://os1.ru/article/14880-chto-uskolzaet-ot-vnimaniya-pri-vypolneniitehobslujivaniya-musorovozov-musorovoz-proverim-samochuvstvie (accessed June 21, 2019). 